\title{
Variations in small mammal helminths structure during host population peak and decline periods and according to locality
}

\author{
Veronika Karešová ${ }^{1}$, Ivana Jankovská ${ }^{1}$, Markéta Zárybnická ${ }^{1}$, Marek Kouba ${ }^{1}$, Richard \\ Ševčík $^{1}$, and Iva Langrová ${ }^{1}$ \\ ${ }^{1}$ Czech University of Life Sciences Prague
}

October 5, 2020

\begin{abstract}
Our results indicated that $64 \%$ (38/59) of small mammals (Apodemus flavicolis, A. sylvaticus, Myodes glareolus, Microtus agrestris, M. arvalis, Sorex araneus and S. minutus) studied in 2015 were infected with Syphacia, Trichuris, Aonchotheca, Heligmosomidae and tapeworms, and $64 \%(27 / 42)$ of animals investigated in 2018 were infected with Syphacia, Trichuris, Aonchotheca, Heligmosomidae and tapeworms. In 2018, prevalence of infection was $83 \%(15 / 18)$ in autumn in NW Bohemia and $50 \%(12 / 24)$ in autumn 2018 in South-East Bohemia. Regarding locality, total prevalence of infection and species richness were higher in North-West Bohemia. Total prevalence of infection according to season was $72 \%(18 / 25)$ in spring and $62 \%$ $(47 / 76)$ in autumn. In NW Bohemia in 2015, $72 \%(18 / 25)$ of animals were infected in spring and $59 \%(20 / 34)$ in autumn. Statistically significant differences in parasite infection of Murinae and Arvicolinae were evident when comparing years and seasons.
\end{abstract}

\section{Hosted file}

Variations in small mammal helmints structure during host population peak and decline periods and accor available at https://authorea.com/users/364438/articles/484992-variations-in-small-mammalhelminths-structure-during-host-population-peak-and-decline-periods-and-according-tolocality 


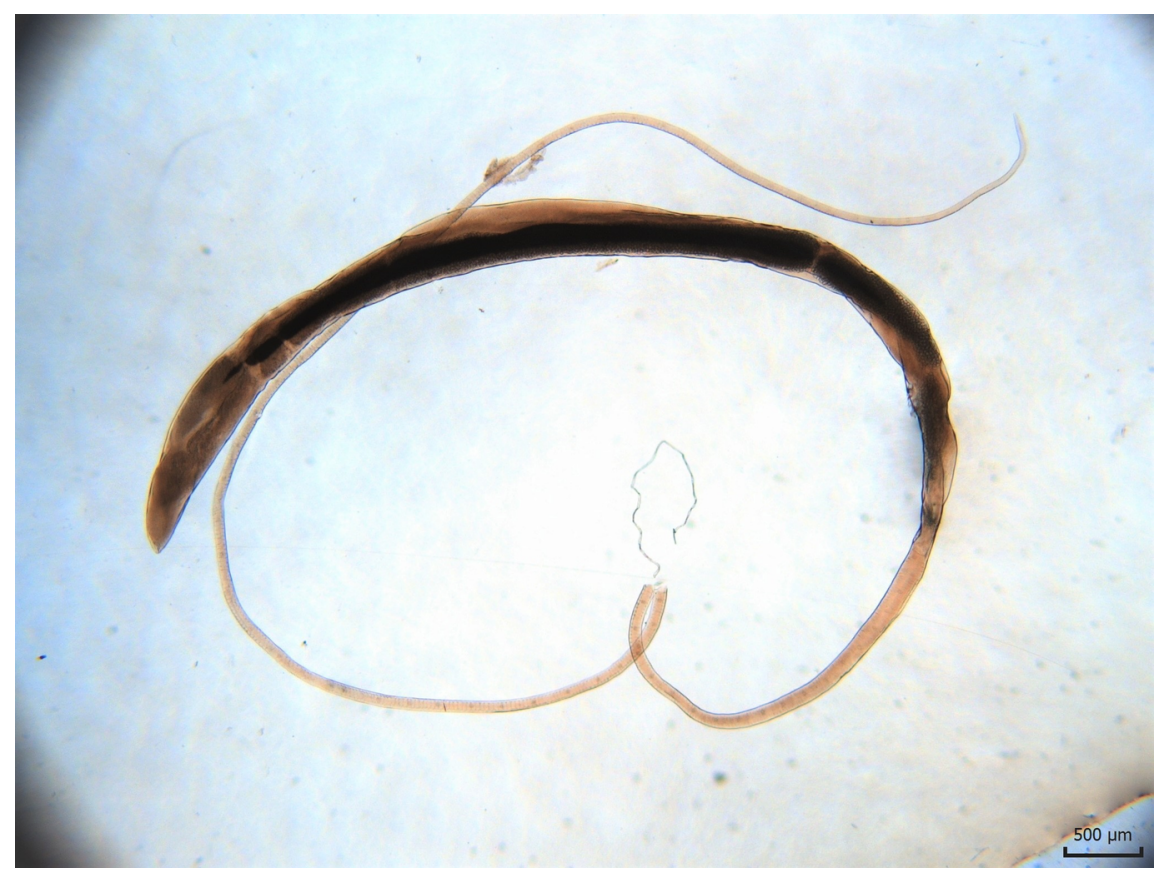

